\begin{tabular}{|c|l|}
\hline Title & Changes in mass and stress during anodic oxidation and cathodic reduction of the Cu/Cu20 multilayer film \\
\hline Author(s) & Seo, Masahiro; Hagioi, Machiko \\
\hline Citation & $\begin{array}{l}\text { Corrosion Science, 49(1), 176-185 } \\
\text { https://doi.org/10.1016/.corsci.2006.05.016 }\end{array}$ \\
\hline Issue Date & 2007-01 \\
\hline Doc URL & http://hdl.handle.net/2115/18855 \\
\hline Type & article (author version) \\
\hline File Information & CS49-1.pdf \\
\hline
\end{tabular}

Instructions for use 


\title{
Changes in mass and stress during anodic oxidation and cathodic reduction of
} the $\mathrm{Cu} / \mathrm{Cu}_{2} \mathrm{O}$ multilayer film

\author{
Masahiro Seo*, Machiko Hagioi \\ Graduate School of Engineering, Hokkaido University, \\ Kita-13 Jo, Nishi-8 Chome, Kita-ku, Sapporo 060-8628, Japan
}

Received 14 September 2005; accepted 12 October 2005

\begin{abstract}
The anodic oxidation and cathodic reduction processes of the $\mathrm{Cu} / \mathrm{Cu}_{2} \mathrm{O}$ multilayer film and pure $\mathrm{Cu}$ film in $\mathrm{pH} 8.4$ borate buffer solution were analyzed by electrochemical quartz crystal microbalance (EQCM) for gravimetry and bending beam method (BBM) for stress measurement. The mass loss of the multilayer film during anodic oxidation at $0.8 \mathrm{~V}$ (SHE) in the passive region was less than that of the pure $\mathrm{Cu}$ film. The comparison between current transients and mass changes during anodic oxidation has succeeded in separating the anodic current density into two partial current densities of oxide film growth, $i_{O^{2-}}$, and of $\mathrm{Cu}^{2+}$ dissolution through the passive film, $i_{\mathrm{Cu}^{2+}}$. As a result, in the case of the pure $\mathrm{Cu}$ film, the anodic current density was mainly due to $i_{\mathrm{Cu}^{2+}}$, while in the case of the multilayer film, $i_{\mathrm{Cu}^{2+}}$ was almost equal to $i_{O^{2-}}$. The compressive stress for the multilayer film was generated during anodic oxidation, while the tensile stress for the pure $\mathrm{Cu}$ film was generated.

The mass loss of the multilayer film during cathodic reduction at a constant current density $\left(i_{c}=-20 \mu \mathrm{A} \mathrm{cm} \mathrm{cm}^{-2}\right)$ was significantly less than that estimated from coulometry, suggesting that $\mathrm{H}_{2} \mathrm{O}$ produced by cathodic reduction remained in the multilayer film.. The compressive stress was generated during cathodic reduction of the multilayer film, which was
\end{abstract}


ascribed to $\mathrm{H}_{2} \mathrm{O}$ remained in the multilayer film.

Keywords: A. $\mathrm{Cu} / \mathrm{Cu}_{2} \mathrm{O}$ multilayer film; B. EQCM; B. Bending beam method; B. Gravimetry; B. Stress measurement; C. Anodic oxidation; C. Cathodic reduction

*Corresponding author. Tel. / fax : +81-11-706-6735.

E-mail address: seo@elechem1-mc.eng.hokudai.ac.jp (M. Seo). 


\section{Introduction}

Copper has been widely used as key materials in microelectronics such as interconnections in integarted cuircuits because of its superier electronic conductivity and high electromigration resistance as compared to aluminum. The fundamental knowledge of the copper passivation and of the structure of anodic oxide film on copper is essentailly necessary for further development of microelectronics and of its related industry. It has been recently found that multilayer films of $\mathrm{Cu}$ and $\mathrm{Cu}_{2} \mathrm{O}$ are electrodeposited from alkaline solutions of $\mathrm{Cu}(\mathrm{II})$ lactate at room temperature, accompanying spontaneous oscillation of electrode potential [1-3]. Moreover, it has been revealed that the $\mathrm{Cu} / \mathrm{Cu}_{2} \mathrm{O}$ multilayer films have the specular reflectance spectra with blue-shift due to quantum-confined effect of layered nanostructure and the anisotropic resistivities ranged from $10^{-4} \mathrm{ohm} \mathrm{cm}$ to $10^{6} \mathrm{ohm}$ $\mathrm{cm}$, depending on $\mathrm{Cu}$ content in the multilayer films [4]. The $\mathrm{Cu} / \mathrm{Cu}_{2} \mathrm{O}$ multilayer films, therefore, will be situated under a variety of potential applications for microelectronics and optoelectronics. The chemical and mechanical stabilities of the $\mathrm{Cu} / \mathrm{Cu}_{2} \mathrm{O}$ multilayer films as well as surface oxide films on copper in environments are of great importance for their applications.

There have been many studies on chemical and semiconductive properties [5-7 ] of surface oxide films on copper in relation to their chemical stabilities. An electrochemical quartz crystal microbalance (EQCM) is powerful and useful for evaluation of chemical stabilities of thin metal films in aqueous environments $[8,9]$ because it is capable of measuring simultaneously small changes in mass and current density. The measurement of stresses generated in films is indispensable for evaluation of their mechanical stabilities. However, the studies on stresses of surface oxide films on copper were few because there were no reliable tools for measurement of small changes in stress. In our previous studies 
$[10,11]$, it has been reported that a bending beam method (BBD) is effective and reliable for measurement of small changes in stress.

In this study, the changes in mass and stress during anodic oxidation and cathodic reduction of $\mathrm{Cu} / \mathrm{Cu}_{2} \mathrm{O}$ multilayer and pure copper films in $\mathrm{pH} 8.4$ borate solution were measured by using EQCM and BBM to discuss from the viewpoint of chemical and mechanical stabilities of these films in aqueous environments.

\section{Experimental}

\section{1. $E Q C M$}

A QCM sensor head (5 MHz, AT- cut quartz crystal : MAXTEK Co.) with an oscillator circuit was employed for experiments. Gold electrodes were evaporated on both sides of the quartz crystal. According to Sauerbrey's equation [12], the mass sensitivity of the quartz oscillator is $\frac{\Delta m}{\Delta f}=-1.77 \times 10^{-8} \mathrm{~g} \mathrm{~cm}^{-2} \mathrm{~Hz}^{-1}$. One side of the gold electrodes with a surface area of $1.32 \mathrm{~cm}^{2}$ was exposed to solution as a working electrode.

\section{2. $B B M$}

The principle and apparatus of a bending beam method (BBM) for measurement of changes in stress were described elsewhere $[10,11,13]$. A titanium film with a thickness of $20 \mathrm{~nm}$ was precoated by evaporation on one side of a thin glass plate (thickness, $t_{s}=150 \mu \mathrm{m}$; width, $5.0 \mathrm{~mm}$; length, $60 \mathrm{~mm}$; Young's modulus, $E_{\mathrm{s}}=70.9 \mathrm{GPa}$; Poisson's ratio; $v_{s}=0.23$ ) for good adhesion, and then a gold film with a thickness of $200 \mathrm{~nm}$ was evaporated on the glass plate as a working electrode. The working electrode was placed vertically into an electrochemical cell with an optical window through which a laser beam of $\mathrm{He}-\mathrm{Ne}$ was irradiated to the glass plate side of the working electrode at a normal incidence angle. The reflected beam was directed toward a position-sensitive photodetector (PSD, Hamamatsu, Inc., 
$\mathrm{S} 1300)$ located at a distance of $W=0.60 \mathrm{~m}$ from the working electrode. The distance between the solution level and reflection point of the laser beam, $L$, was $40 \mathrm{~mm}$. The changes in $\mathrm{dc}$ output signals of the PSD were converted into the changes in position, $\Delta h$, of the reflection beam on the PSD.

The changes in reflection angle, $\Delta \theta$, of the laser beam due to bending of the glass plate caused by stress generation in film are given by

$$
\Delta \theta=\frac{\Delta h}{n_{s} W}
$$

where $n_{\mathrm{s}}$ is the refractive index of the solution. The insertion of $n_{\mathrm{s}}$ into Eq. 1 is indispensable bacause the reflected beam is refractive at the solution / air interface. The changes in reciprocal to the curvature radius of bending of the glass plate, $\Delta(1 / R)$, are directly related to the changes in reflection angle, $\Delta \theta$, as follows

$$
\Delta\left(\frac{1}{R}\right)=\frac{\Delta \theta}{2 L}
$$

In the case where the thickness of film, $t_{\mathrm{f}}$, is sufficiently less than that of the substrate, $t_{\mathrm{s}}$, the changes in stress per unit thickness, $\Delta \sigma$, generated in film are given by the Stoney's equation [14]

$$
\Delta \sigma=\frac{\Delta g}{t_{f}}=\frac{E_{s} t_{s}^{2}}{6\left(1-v_{s}\right) t_{f}} \Delta\left(\frac{1}{R}\right)
$$

where $\Delta g$ is the stress for whole film thickness with a dimension of Newton per meter, corresponding to surface stress. The use of $\Delta g$ in place of $\Delta \sigma$ may be convenient in the case where $t_{\mathrm{f}}$ is unknown or not exactly determined.

\section{Preparation and anodic oxidation / cathodic reduction of the $\mathrm{Cu} / \mathrm{Cu}_{2} \mathrm{O}$ multilayer film}

The multilayer film which consisted of four sets of $\mathrm{Cu}_{2} \mathrm{O}$ layer with a thickness of 1-2 $\mathrm{nm}$ and of $\mathrm{Cu}$ layer with a thickness of 8-9 $\mathrm{nm}$ was electrodeposited on gold electrode under a constant current density of $-0.5 \mathrm{~mA} \mathrm{~cm}^{-2}$ from a $\mathrm{pH}$ 9.0, mixed aqueous solution of 
$0.6 \mathrm{M} \mathrm{CuSO}_{4}+3 \mathrm{M}$ lactate. The composition and thickness of each layer were calculated from the derivative of mass with electric charge, $\Delta m / \Delta Q$, and the electric charge, $Q$, corresponding to the period of potential oscillation during electrodeposition by using EQCM. As reported by Bohannan et al. [3], the $\mathrm{Cu}$ layer was not pure $\mathrm{Cu}$ layer but a composite of $\mathrm{Cu}$ and $\mathrm{Cu}_{2} \mathrm{O}(3: 2)$. The pure copper film with a thickness of $800 \mathrm{~nm}$ was also electroplated on gold electrode under a constant current density of $-10.0 \mathrm{~mA} \mathrm{~cm}^{-2}$ from a mixed aqueous solution of $0.8 \mathrm{M}$ $\mathrm{CuSO}_{4}+0.5 \mathrm{M} \mathrm{H}_{2} \mathrm{SO}_{4}$. The electrolyte solution used for experiment was $\mathrm{pH} 8.4$ borate solution which was deaerated with ultra-pure argon gas before and during experiment. The anodic oxidation of the $\mathrm{Cu} / \mathrm{Cu}_{2} \mathrm{O}$ multilayer and pure $\mathrm{Cu}$ films was potentiostatically performed in the passive potential region, while the cathodic reduction was galvanostatically carried out $\left(i_{\mathrm{c}}=-20 \mu \mathrm{A} \mathrm{cm}^{-2}\right)$.

\section{Results and discussion}

\subsection{Anodic oxidation of the $\mathrm{Cu} / \mathrm{Cu}_{2} \mathrm{O}$ multilayer film.}

Fig. 1 shows the time variation of anodic current density, $i$, and mass change, $\Delta m$, for the multilayer film and pure copper film during anodic oxidation at $0.8 \mathrm{~V}(\mathrm{SHE})$ in the passive region in $\mathrm{pH} 8.4$ borate solution. For a better understanding of anodic oxidation process, it may be useful to separate real anodic current density, $i_{\text {real }}$, into two partial current densities of copper dissolution through the film, $i_{\mathrm{Cu}^{2+}}$, and of film growth, $i_{O^{2-}}[15,16]$.

$$
i_{\text {real }}=i_{C u^{2+}}+i_{O^{2-}}
$$

Assuming that the anodic dissolution of copper as $\mathrm{Cu}^{+}$through the film is negligibly small, the net mass loss rate, $\frac{d m_{T}}{d t}$, is the summation of the mass loss rate, $\frac{d m_{C u^{2+}}}{d t}$ due to copper dissolution as $\mathrm{Cu}^{2+}$ through the film and the mass gain rate of film growth, $\frac{d m_{O^{2-}}}{d t}$, due to oxygen uptake. 
$\frac{d m_{T}}{d t}=\frac{d m_{C u^{2+}}}{d t}+\frac{d m_{O^{2-}}}{d t}$

The following relation between each partial current density and mass gain or loss rate will be held.

$$
\begin{aligned}
& i_{C u^{2+}}=\left(\frac{2 F}{M_{C u}}\right)\left(\frac{d m_{C u^{2+}}}{d t}\right) \\
& i_{O^{2-}}=-\left(\frac{2 F}{M_{O}}\right)\left(\frac{d m_{O^{2-}}}{d t}\right)
\end{aligned}
$$

where $\mathrm{M}_{\mathrm{Cu}}$ is the atomic weight of copper, $\mathrm{M}_{\mathrm{O}}$, the atomic weight of oxygen, and $\mathrm{F}$ is the Faraday constant. Furthermore, $i_{a p p}$ will be defined as follows.

$$
i_{\text {app }}=\left(\frac{2 F}{M_{C u}}\right)\left(\frac{d m_{T}}{d t}\right)
$$

Eventually, Eq. (8) will be derived by substituting Eqs.(5), (6a) and (6b) for Eq. (7).

$$
i_{\text {app }}=i_{C u^{2+}}-\left(\frac{M_{O}}{M_{C u}}\right) i_{O^{2-}}
$$

Since $i_{\text {real }}$ is measured and $i_{\text {app }}$ is known from Eq. (7), $i_{\text {real }}$ can be separated into $i_{C u^{2+}}$ and $i_{O^{2-}}$ by using Eqs. (4) and (8).

Fig. 2 shows $i_{\mathrm{Cu}^{2+}}$ and $i_{\mathrm{O}^{2-}}$ as a function of time for the pure copper film (a) and the $\mathrm{Cu} / \mathrm{Cu}_{2} \mathrm{O}$ multilayer film (b). For the pure copper film (a), $i_{O^{2-}}$ is very small as compared to $i_{C u^{2+}}$ except for the initial stage, while for the $\mathrm{Cu} / \mathrm{Cu}_{2} \mathrm{O}$ multilayer film, $i_{O^{2-}}$ is nearly equal to $i_{C u^{2+}}$. This means that the copper dissolution through the film is predominant in anodic oxidation of the pure copper film, while the oxgen uptake in the multilayer film continues up to the late stage. It is known that a duplex oxide film consisting of $\mathrm{CuO}$ as an outer layer and $\mathrm{Cu}_{2} \mathrm{O}$ as an inner layer grows during anodic oxidation of copper [5-7]. The duplex oxide film would also grow during anodic oxidation of the multilayer film. The pre-exisitence of $\mathrm{Cu}_{2} \mathrm{O}$ 
layers in the multilayer film may influence the transport of mobile ion such as $\mathrm{Cu}^{+}, \mathrm{Cu}^{2+}$ or $\mathrm{O}^{2-}$ in the film during anodic oxidation. The results of Fig. 2 suggest that anodic oxidation of the pure copper film proceeds exclusively with outward tarnsport of cations $\left(\mathrm{Cu}^{+}\right.$or $\left.\mathrm{Cu}^{2+}\right)$, while inward transport of $\mathrm{O}^{2-}$ participate significantly in anodic oxidation of the multilayer film. Fig. 3 shows the time variation of anodic current density, $i$, and the changes in stress, $\Delta g$, during anodic oxidation of the multilayer film and pure copper film under the same conditions in Fig.1. In Fig. 3, the changes in stress to tensile direction were taken as a positive sign, while the changes in stress to compressive direction were taken as a negative sign. It is seen from Fig. 3 that the commpressive stress is generated and increases with time during anodic oxidation of the multilayer film. In contrast, the tensile stress is generated and increases wirth time during anodic oxidation of the pure copper film. The parameters influencing the direction of stress generated during oxide film growth are the transport number of mobile ion and Pilling-Bedworth $(\mathrm{PB})$ ratio of oxide [17]. According to the criteria proposed by Nelson and Oriani [17], in the case where the transport number of cation is nearly unity, the tensile stress is generated, while in the case where the transport number of anion is nearly unity, the compressive stress is generated. It appears that the results of Fig. 3 are consistent with those of Fig. 2.

\subsection{Cathodic reduction of the $\mathrm{Cu} / \mathrm{Cu}_{2} \mathrm{O}$ multilayer film.}

Fig. 4 shows the potential decay and mass change curves during cathodic reduction of the multilayer film at a constant current density of $-20 \mu \mathrm{A} \mathrm{cm}^{-2}$ in $\mathrm{pH} 8.4$ borate solution. The potential plateau at about $-0.18 \mathrm{~V}(\mathrm{SHE})$ corresponds to the cathodic reduction of $\mathrm{Cu}_{2} \mathrm{O}$ to metallic $\mathrm{Cu}$.

$$
\mathrm{Cu}_{2} \mathrm{O}+2 \mathrm{H}^{+}+2 e^{-} \rightarrow 2 \mathrm{Cu}+\mathrm{H}_{2} \mathrm{O}
$$

The dotted line represents the theoretical mass change due to cathodic reduction of $\mathrm{Cu}_{2} \mathrm{O}$ in 
the multilayer film, assuming that the reaction of Eq. (9) proceeds with $100 \%$ current efficiency. In the potential plateau region, however, the mass loss is very small as compared to the theoretical line in spite of that the reaction of Eq. (9) takes place. This means that $\mathrm{H}_{2} \mathrm{O}$ molecules produced by cathodic reduction of $\mathrm{Cu}_{2} \mathrm{O}$ remain in the film. Since in the multilayer film, each $\mathrm{Cu}_{2} \mathrm{O}$ layer is sandwiched in two $\mathrm{Cu}$-rich composite layers, $\mathrm{H}^{+}$ions migrate inward, passing through the outer metallic $\mathrm{Cu}$ layer produced by cathodic reduction of $\mathrm{Cu}_{2} \mathrm{O}$, reaching the inner $\mathrm{Cu}_{2} \mathrm{O}$ layer and react it to produce $\mathrm{H}_{2} \mathrm{O}$ molecules. The produced $\mathrm{H}_{2} \mathrm{O}$ molecules, however, seem difficult to diffuse outward through the outer metalllic $\mathrm{Cu}$ layer. The molar volumes of $\mathrm{Cu}$ and $\mathrm{Cu}_{2} \mathrm{O}$ are $7.1 \mathrm{~cm}^{3} \mathrm{~mol}^{-1}$ and $23.7 \mathrm{~cm}^{3} \mathrm{~mol}^{-1}$, respectively. The outer metallic $\mathrm{Cu}$ layer produced by reduction of $\mathrm{Cu}_{2} \mathrm{O}$ would have a free space of $4.8 \mathrm{~cm}^{3} \mathrm{~mol}^{-1}$ to form a porous structure through which $\mathrm{H}^{+}$ions can pass easily. Nevertheless, the outward diffusion of the produced $\mathrm{H}_{2} \mathrm{O}$ molecules may be supressed in the case where the channel size for outward diffusion of $\mathrm{H}_{2} \mathrm{O}$ molecules is less than the average pore size of the outer metallic $\mathrm{Cu}$ layer.

Fig. 5 shows the potential decay and stress change curvesunder the same conditions in Fig. 4. The compressive stress is generated in the time domain up to $t=1.2 \mathrm{ks}$ and then the stress changes from compressive to tensile direction. At the final stage, the stress jumps further to the tensile direction in responses to the rapid changes in $E$ and $\Delta m$ (see Fig.4). The generation of compressive stress up to the intermediate stage $(t=1.2 \mathrm{ks})$ may be associated with remaining of $\mathrm{H}_{2} \mathrm{O}$ molecules in the outer metallic $\mathrm{Cu}$ layer because of the net volume expansion due to remaining of $\mathrm{H}_{2} \mathrm{O}$ molecules produced during cathodic reduction of $\mathrm{Cu}_{2} \mathrm{O}$ to metallic $\mathrm{Cu}$. The molar volume of $\mathrm{H}_{2} \mathrm{O}$ at $298 \mathrm{~K}$ is $18.05 \mathrm{~cm}^{3} \mathrm{~mol}^{-1}$ and thus the volume expansion $\left(\Delta V=9.0 \mathrm{~cm}^{3} \mathrm{~mol}^{-1}\right)$ due to remaining of $\mathrm{H}_{2} \mathrm{O}$ overcomes the volume contraction $\left(\Delta V=-4.8 \mathrm{~cm}^{3} \mathrm{~mol}^{-1}\right)$ due to conversion of $\mathrm{Cu}_{2} \mathrm{O}$ to metallic $\mathrm{Cu}$. The stress change from compressive to tensile direction at $t>1.2 \mathrm{ks}$ may be caused by crack formation of the outer 
metallic $\mathrm{Cu}$ layer which releases partly the compressive stress. Assuming that the multilayer film is cathodically reduced by $50 \%$ at $t=1.2 \mathrm{ks}$, the estimated thickness of the outer metallic $\mathrm{Cu}$ layer is about $30 \mathrm{~nm}$. The change in compressive stress up to $t=1.2 \mathrm{ks}$ is $\Delta g=-15 \mathrm{~J} \mathrm{~m}^{-2}$ as shown in Fig. 5. The level of compressive stress accumulated in the outer metallic Cu layer is estimated to be about $\Delta \sigma=-0.5 \mathrm{GPa}$ [18], which exceeds the compressive strength of $\mathrm{Cu}$ (about - $0.2 \mathrm{GPa}$ ). This means that the outer metallic $\mathrm{Cu}$ layer is situated under the compressive stress conditions sufficient for crack formation. The further stress jump to the tensile direction at the final stage of cathodic reduction accompanies both rapid potential drop and mass loss as seen from Fig. 4. The rapid potential drop may trigger the stress jump to the tensile direction and contribute to the rapid release of $\mathrm{H}_{2} \mathrm{O}$ molecules from the outer metallic $\mathrm{Cu}$ layer, although its mechanism is not clear at present.

\section{Conclusions}

The changes in mass and stress during anodic oxidation and cathodic reduction processes of the $\mathrm{Cu} / \mathrm{Cu}_{2} \mathrm{O}$ multilayer film as well as pure copper film in $\mathrm{pH} 8.4$ borate solution were measured by EQCM and BBM. The following conclusions were drawn.

1. The anodic current density, $i$, during anodic oxidation at $0.8 \mathrm{~V}$ (SHE) in the passive region could be separated into two partial current densities of copper dissolution as $\mathrm{Cu}^{2+}, i_{\mathrm{Cu}}^{2+}$, and of oxide film growth, $i_{O^{2-}}$.

2. For the pure copper film, $i_{O^{2-}}$ was very small as compared to $i_{\mathrm{Cu}^{2+}}$ except for the initial stage, while for the multilayer film, $i_{\mathrm{O}^{2-}}$ was nearly equal to $i_{\mathrm{Cu}^{2+}}$. Moreover, $i_{\mathrm{Cu}^{2+}}$ for the multilayer film was less than that for the pure copper film, indicating that copper dissolution as $\mathrm{Cu}^{2+}$ was suppressed by $\mathrm{Cu}_{2} \mathrm{O}$ in the multilayer film.

3. The compressive stress for the multilayer film was generated during anodic oxidation, 
while the tensile stress for the pure $\mathrm{Cu}$ film was generated. The difference in direction of stress generation between multilayer film and pure copper film was associated with the difference in $i_{\mathrm{Cu}^{2+}}$ or $i_{\mathrm{O}^{2-}}$ between both films.

4. The mass loss of the multilayer film during cathodic reduction was significantly less than that estimated from coulometry, suggesting that $\mathrm{H}_{2} \mathrm{O}$ produced by cathodic reduction remained in the multilayer film..

5. The compressive stress was generated during cathodic reduction of the multilayer film, which was ascribed to $\mathrm{H}_{2} \mathrm{O}$ remained in the multilayer film.

\section{References}

[1] J. A. Switzer, C.-J. Hung, E. W. Bohannan, M. G. Shumsky, T. D. Golden, D. C. Van Aken, Adv. Mater. 9(4) (1997) 334-338.

[2] J. A. Switzer, C.-J. Hung, L.-Y. Huang, F. S. Miller, Y. Zhou, E. R. Rauh, M. G. Shumsky, E. W. Bohannan, J. Mater. Res. 13 (4)(1998)909-916.

[3] E. W. Bohannan, L.-Y. Huang, F. S. Miller, M. G. Shumsky, J. A. Switzer, Langmuir $15(3)(1999) 813-818$.

[4] J. A. Switzer, C.-J. Hung, L.-Y. Huang, E. R. Switzer, D. R. Kammler, T. D. Golden, E. W. Bohannan, J. Am. Chem. Soc. 120 (14) (1998)3530-3531.

[5] H. -D. Speckmann, M. M. Lohrengel, J. W. Schultze, H. -H. Strehblow, Ber. Bunsenges. Phys. Chem. 89 (1985) 392-402.

[6] M. M. Lohrengel, J. W. Schultze, H. D. Speckmann, H. -H. Strehblow, Electrochim. Acta 32(5) (1987)733-742.

[7] J. Kunze, V. Maurice, L. H. Klein, H. -H. Strehblow, P. Marcus, Corros. Sci. 46 (2004) 245-264.

[8] M. Seo, K. Yoshida, K. Noda, Mater. Sci. Eng. A198 (1995)197-203. 
[9] M. Kurosaki, M. Seo, Corros. Sci. 45 (2003) 2597-2607.

[10] K. Ueno, S. -I. Pyun, M. Seo, J. Electrochem. Soc. 147(12) (2000) 4519-4523.

[11] M. Seo, M. Yamazaki, J. Electrochem. Soc. 151(8) (2004) E276-E281.

[12] G. Sauerbrey, Z. Phys. 155 (1959) 206-222.

[13] G. G. Láng, M. Seo, J. Electroanal. Chem. 490 (2000) 98-101.

[14] G. G. Stoney, Proc. R. Soc. Lond. A82 (1909) 172-175.

[15] L. Grasjö, M. Seo, N. Sato, Corros. Sci. 31 (1990) 199-304.

[16] M. Seo, H. Tsuda, Electrochem. Soc. Proc. 99-27 (1999) 280-289.

[17] J. C. Nelson, R. A. Oriani, Corros. Sci., 34 (2) (1993)307-326. 


\section{Figure Captions}

Fig. 1 Time variation of anodic current density, $i$, and mass change, $\Delta \mathrm{m}$, for the multilayer film and pure copper film during anodic oxidation at $0.8 \mathrm{~V}$ (SHE) in $\mathrm{pH} 8.4$ borate solution.

Fig. 2 Time variation of real current density, $i_{\text {real }}$, partial current density of copper dissolution, $i_{\mathrm{Cu}^{2+}}$, and partial current density of film growth, $i_{\mathrm{O}^{2-}}$ for the pure copper film (a) and multilayer film (b) during anodic oxidation at $0.8 \mathrm{~V}$ (SHE) in $\mathrm{pH} 8.4$ borate solution.

Fig. 3 Time variation of anodic current density, $i$, and stress change, $\Delta \mathrm{g}$, for the multilayer film and pure copper film during anodic oxidation at $0.8 \mathrm{~V}$ (SHE) in $\mathrm{pH} 8.4$ borate solution.

Fig. 4 Potential decay and mass change curves for the multilayer film during cathodic reduction at a current density of $-20 \mu \mathrm{A} \mathrm{cm}^{-2}$ in $\mathrm{pH} 8.4$ borate solution.

Fig. 5 Potential decay and stress change curves for the multilayer film during cathodic reduction at a current density of $-20 \mu \mathrm{A} \mathrm{cm}^{-2}$ in $\mathrm{pH} 8.4$ borate solution. 


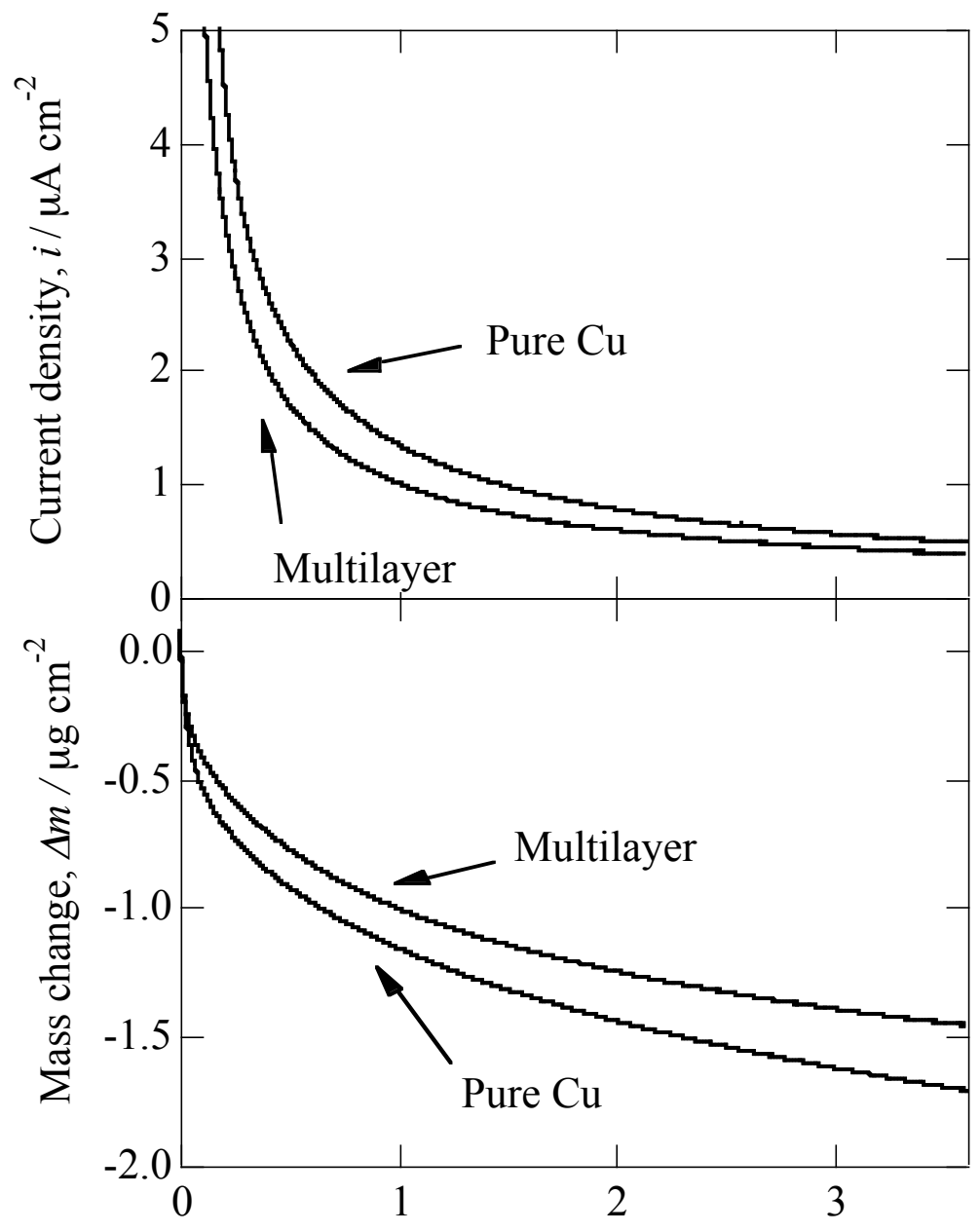

Time, $t$ / ks

Fig. 1 Time variation of anodic current density, $i$, and mass change , $\Delta m$, for the multilayer film and pure copper film during anodic oxidation at $0.8 \mathrm{~V}$ (SHE) in $\mathrm{pH} 8.4$ borate solution. 


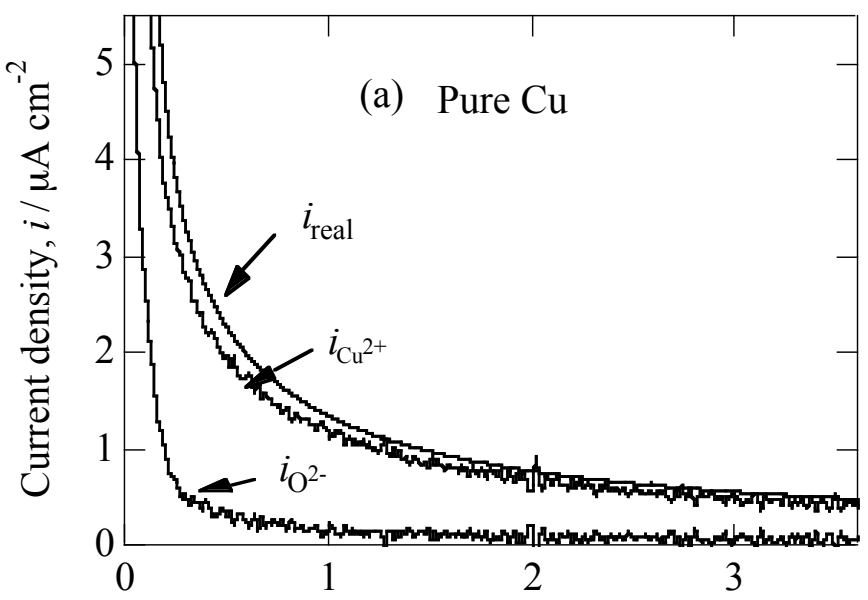

Time, $t / \mathrm{ks}$

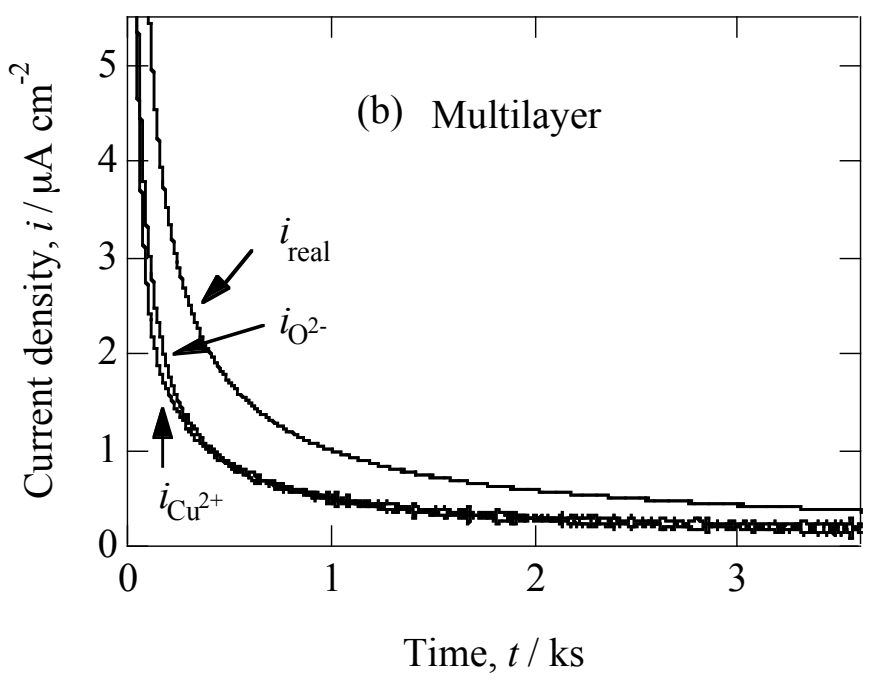

Fig. 2 Time variation of real current density, $i_{\text {real }}$, partial current density of copper dissolution, $i_{\mathrm{Cu}^{2+}}$, and partial current density of film growth, $i_{\mathrm{O}^{2-}}$, for the pure copper film (a) and multilayer film (b) during anodic oxidation at $0.8 \mathrm{~V}$ (SHE) in $\mathrm{pH} 8.4$ borate solution. 


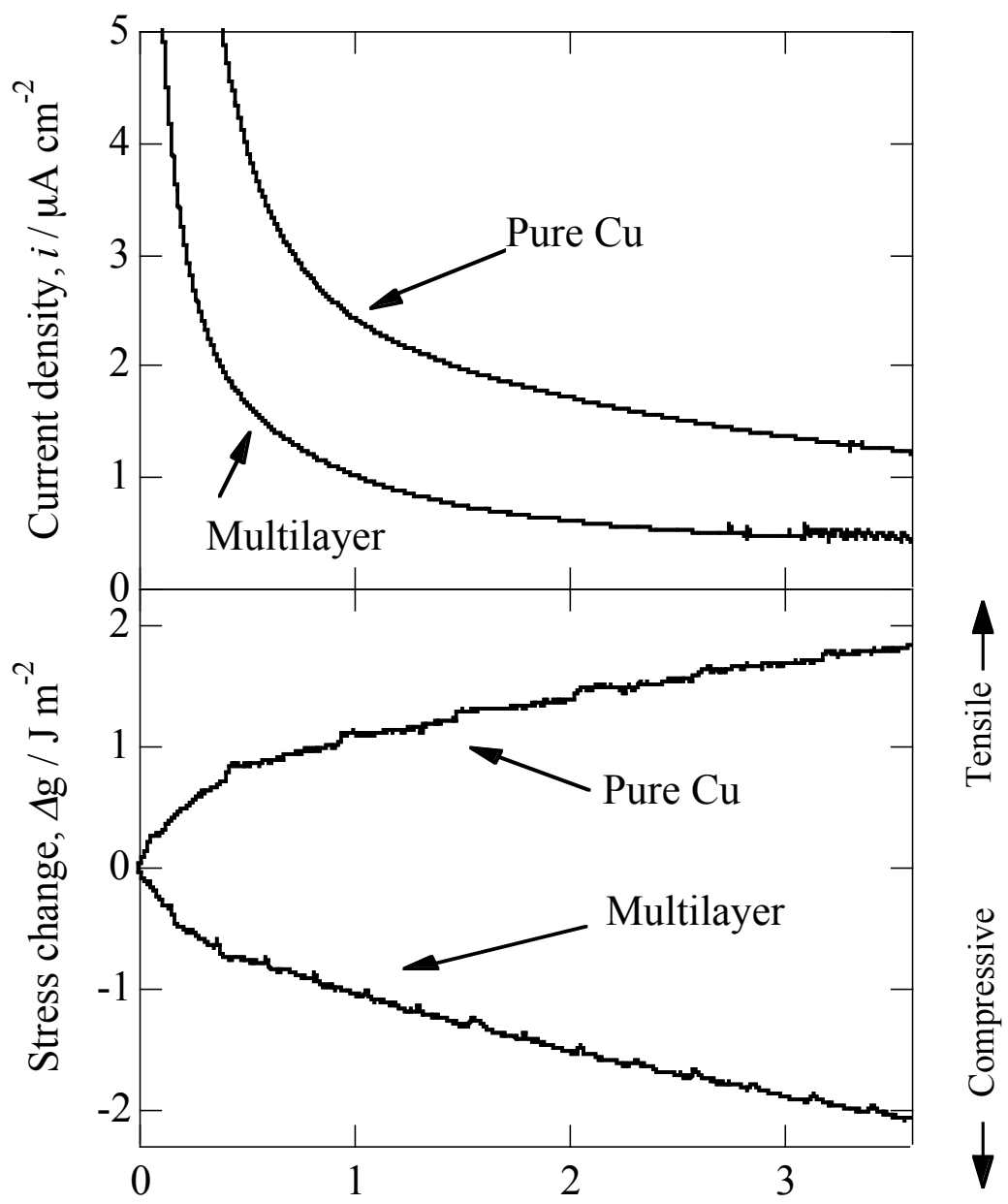

Time, $t / \mathrm{ks}$

Fig. 3 Time variation of anodic current density, $i$, and stress change ,$\Delta \mathrm{g}$, for the multilayer film and pure copper film during anodic oxidation at $0.8 \mathrm{~V}$ (SHE) in $\mathrm{pH} 8.4$ borate solution. 


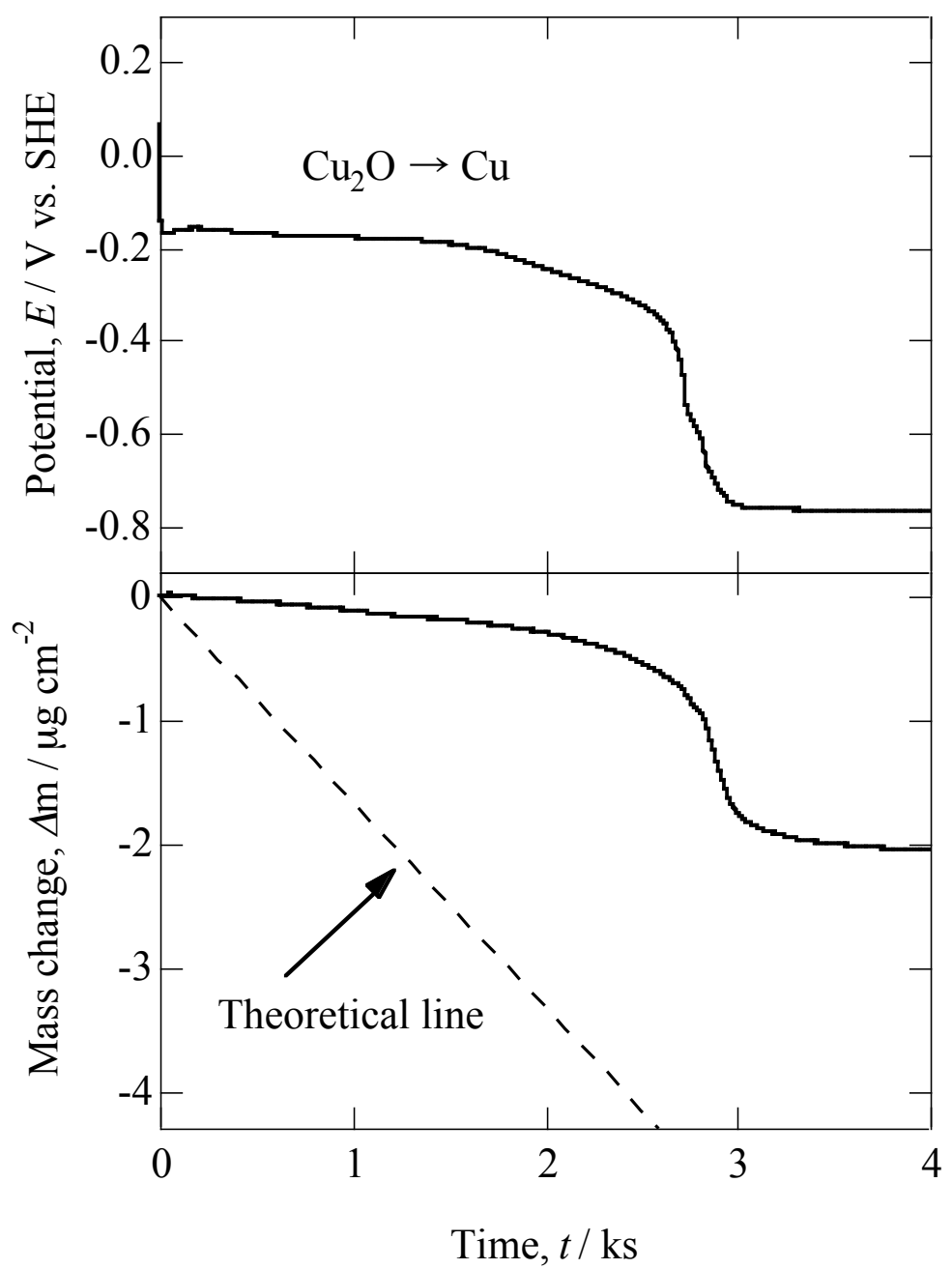

Fig. 4 Potential decay and mass change curves for the multilayer film during cathodic reduction at a constant current density of $-20 \mu \mathrm{A} \mathrm{cm}^{-2}$ in $\mathrm{pH} 8.4$ borate solution. 


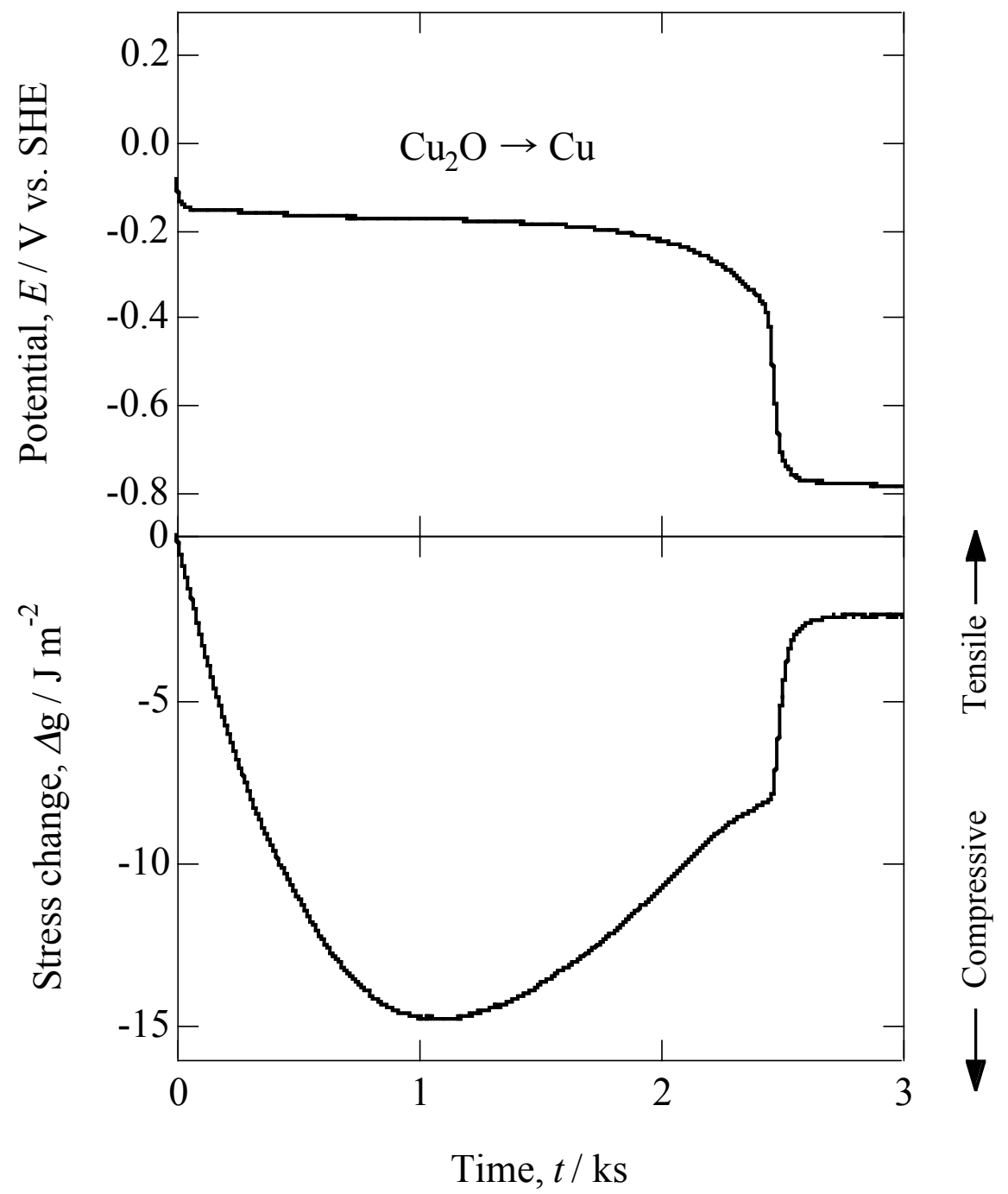

Fig. 5 Potential decay and stress change curves for the multilayer film during cathodic reduction at a constant current density of $-20 \mu \mathrm{A} \mathrm{cm}^{-2}$ in $\mathrm{pH} 8.4$ borate solution. 